\title{
Bactericidal and Virucidal Activity of Povidone-Iodine and Chlorhexidine Gluconate Cleansers in an In Vivo Hand Hygiene Clinical Simulation Study
}

\author{
Maren Eggers · Torsten Koburger-Janssen - Lois S. Ward • \\ Craig Newby $\cdot$ Stefan Müller
}

Received: February 6, 2018 / Published online: May 14, 2018

(C) The Author(s) 2018

\begin{abstract}
Introduction: Standard in vitro and in vivo tests help demonstrate efficacy of hand hygiene products; however, there is no standard in vivo test method for viruses. We investigated the bactericidal and virucidal efficacy of povidoneiodine (PVP-I) 7.5\% scalp and skin cleanser, chlorhexidine gluconate (CHG) 4\% hand cleanser and the reference hand wash (soft soap) in 15 healthy volunteers following European Standard EN1499 (hygienic hand wash test
\end{abstract}

Enhanced Digital Features To view enhanced digital features for this article go to https://doi.org/10.6084/ m9.figshare.6200894.

M. Eggers

Labor Prof Gisela Enders MVZ GbR, Stuttgart, Germany

T. Koburger-Janssen

Hygiene Nord GmbH, Greifswald, Germany

L. S. Ward

Clinical Operations, Mundipharma Research

Limited, Cambridge, UK

C. Newby

R\&D, Mundipharma Manufacturing Pte Ltd, Singapore, Singapore

\section{S. Müller (ه)}

Pharmacologicial and Translational Science,

Mundipharma Research GmbH \& Co KG, Limburg,

Germany

e-mail: stefan.mueller@mundipharma-rd.eu method for bacteria), which was adapted for virucidal testing.

Methods: Separate test series were performed for bactericidal (Escherichia coli) and virucidal [murine norovirus (MNV)] testing. After prewashing and artificial contamination of hands with test organisms, volunteers underwent testing with 3 and $5 \mathrm{~mL}$ of each product for contact times of 15,30 and $60 \mathrm{~s}$ according to a Latin-square randomization. The number of test organisms released from fingertips into sampling fluids was assessed before and after hand washing and mean $\log _{10}$ reduction factor (RF) was calculated. RFs (test-reference) were compared using a Wilcoxon-Wilcox multiple comparisons test per EN1499; efficacy was concluded if $p \leq 0.01$.

Results: PVP-I 7.5\% and CHG 4\% cleansers both passed EN1499 requirements against E. coli, with statistically significantly greater $(p$ $\leq 0.01)$ mean $\log _{10}$ RFs compared with reference soft soap across all tests (PVP-I: 4.09-5.27; CHG: 4.12-5.22; soap: 2.75-3.11). The experimental design using EN1499 was applicable to testing with MNV as discriminatory and reproducible results were generated. Mean $\log _{10}$ RFs of MNV were statistically significantly greater for PVP-I (1.57-2.57) compared with soft soap (1.24-1.62), while mean $\log _{10}$ RFs with CHG (0.90-1.34) were lower than for soft soap across all tests.

Conclusion: PVP-I 7.5\% cleanser showed superior efficacy against MNV compared to soft soap 
and CHG 4\% cleanser, while both PVP-I and CHG were superior to soft soap against E. coli. The experimental set-up may be applicable to future testing for antiviral hand washes.

Funding: Mundipharma Manufacturing Pte Ltd.

Plain Language Summary: Plain language summary available for this article.

Keywords: Antimicrobial wash; Bactericidal activity; Chlorhexidine gluconate; Escherichia coli; Hand-cleansing agents; Hand hygiene; Infection control; Non-enveloped virus; Povidone-iodine; Virucidal activity

\section{PLAIN LANGUAGE SUMMARY}

Serious infectious disease outbreaks and hospital-acquired infections are threats to human health. Effective vaccines and drug products are often not available, but antiseptic products for hand washing can help to control the spread of disease. Standard methods are used to test the effectiveness of hand hygiene products in the laboratory and on the hands of human volunteers.

We used a standard hand washing test method to find out whether two antiseptic products work against bacteria (Escherichia coli). The method was adapted to also test effectiveness against viruses (murine norovirus). The products tested were povidone-iodine scalp and skin cleanser, and chlorhexidine gluconate hand cleanser, which were compared to plain soft soap. After contamination of hands with the bacteria/virus, volunteers washed their hands for 15,30 or $60 \mathrm{~s}$, using 3 or $5 \mathrm{~mL}$ of product, in separate tests. Bacteria/viruses present on volunteers' hands were measured before and after hand washing. The antiseptic product had to remove significantly more bacteria/ viruses than plain soap to be rated as effective.

Povidone-iodine cleanser and chlorhexidine gluconate cleanser were both more effective than plain soap at removing bacteria from volunteers' hands. Povidone-iodine cleanser was more effective than plain soap at removing viruses, except when using $3 \mathrm{~mL}$ product for $15 \mathrm{~s}$. Chlorhexidine gluconate cleanser was less effective than plain soap at removing viruses in all tests. The adapted test method using murine norovirus worked well, giving consistent results for each product, and may be suitable for future testing of antiseptic products against viruses.

\section{INTRODUCTION}

The importance of hand hygiene in health care and community settings is undoubted, with numerous studies demonstrating the association between proper hand hygiene and reductions in both rates of nosocomial infections [1-3] and rates of infectious illnesses in communities [4]. Hand hygiene is also an infection control procedure that can be rapidly adopted by the public and healthcare workers in the case of emerging and re-emerging infectious diseases to limit the spread of viruses by breaking the transmission $[5,6]$.

Multiple hand hygiene agents are currently available including plain non-medicated soap, medicated hand washes with various active ingredients, and waterless or alcohol-based hand rubs. Although the use of alcohol-based hand rubs is convenient, the World Health Organization (WHO) recommends washing hands with soap and water when visibly dirty or visibly soiled with blood or other body fluids [2]. It is recognized that some antiseptics and alcohol-based hand rubs are characterized by resistant bacteria and efficacy gaps [1-3]. In vitro suspension tests and human challenge trials help to demonstrate which hand hygiene agents are fit for purpose, but variations in methodology affect the measurement of efficacy [7]. Ensuring that hand rub and hand wash products pass standardized antimicrobial activity tests helps to better understand and interpret efficacy results [7].

In Europe, the most commonly used methods to test hand antiseptics are those of the European Committee for Standardization (CEN), while in the USA and Canada, the standards of ASTM International (formerly, the American Society for Testing and Materials) are used. The CEN has adopted a hierarchical, systematic approach of product testing. In this concept, European Standards EN1276 and 
EN14476 are established initial in vitro methods to determine the bactericidal and virucidal efficacy of antiseptics and disinfectants $[8,9]$. The next step in the CEN testing scheme is European standard EN1499 (for hand washes) and EN1500 (for hand rubs), each Phase 2/Step 2 hand simulation studies where the hands of volunteers are artificially contaminated with E. coli and the test product is compared against a reference procedure in a crossover design $[10,11]$. To fill in gaps within the in vitro CEN testing, modified vaccinia virus Ankara (MVA) was introduced in 2015 as a reference virus for the claim of virucidal activity against enveloped viruses for hygienic hand rub and hand wash products $[9,12,13]$. However, it has not been possible to develop a Phase 2/Step 2 test for enveloped viruses due to the lack of availability of a safe enveloped virus that can be ethically used in testing on volunteers' hands, and there is currently no standard in vivo test method for viruses. To fill this gap, a hand simulation test has recently been considered that uses murine norovirus (MNV), a non-pathogenic (biosafety level 1) non-enveloped virus, which is more resilient to antiseptics than enveloped viruses, as a model test organism.

Povidone-iodine (PVP-I) and chlorhexidine gluconate (CHG) are broad-spectrum antimicrobials that have been used in infection control and prevention for more than 60 years. PVP-I has well-established general antimicrobial activity, particularly in relation to resistant organisms [2], demonstrating in vitro activity against Gram-positive, Gram-negative and some spore-forming bacteria (Clostridia, Bacillus spp.) and mycobacteria [2, 14-18] and a wide range of enveloped and non-enveloped viruses [12, 13, 19-22]. In contrast, CHG has good in vitro activity against Gram-positive bacteria and enveloped viruses, less activity against Gram-negative bacteria and non-enveloped viruses, and minimal activity against mycobacteria [22-28]. CHG resistance is a concern and has been detected in isolates of Enterobacter spp., Pseudomonas spp., Proteus spp., Providencia spp. and Enterococcus spp [29]. In vivo studies using artificial fingertip contamination have previously shown PVP-I and 70\% ethyl alcohol to be more effective than plain soap in removing methicillin-resistant Staphylococcus aureus (MRSA), Acinetobacter baumannii and E. coli from volunteers' hands, while CHG was only significantly more effective than plain soap at removing E. coli [30-33]. In vivo virucidal studies are generally lacking; however, in a modified finger pad test based on the ASTM E 1838 [34] using MNV, PVP-I was shown to have superior efficacy to three alcohol-based hand rubs while $4 \%$ CHG and $1 \%$ triclosan showed no activity [35].

We undertook two hand hygiene in vivo clinical simulation studies to investigate the bactericidal and virucidal efficacy of PVP-I 7.5\% scalp and skin cleanser and CHG 4\% hand cleanser versus the reference hand wash (soft soap) on healthy volunteers' hands. Both studies followed European standard EN1499 as a function of employed soap volume and hand washing time. The virucidal study was performed in an exploratory manner using murine norovirus (MNV) as model test virus.

\section{METHODS}

\section{Study Design}

Each study was randomized, controlled, open label, crossover and exploratory in design. The bactericidal study was conducted at the laboratories of Hygiene Nord, Greifswald, Germany, from 1 September 2016 to 19 January 2017. The virucidal study was conducted at the laboratories of Labor Prof. Gisela Enders MVZ GbR, Stuttgart, Germany, from 14 September 2016 to 12 December 2016. Hand hygiene tests were performed on the hands of healthy volunteers simulating practical use according to the methods described in European Standard EN1499:2013 (hygienic hand wash test method for bacteria), which were adapted and used in an exploratory manner to assess the virucidal activity of the hand cleansers. All procedures performed in studies involving human participants were in accordance with the 1964 Helsinki declaration and its later amendments or comparable ethical standards. Informed consent was obtained from all individual participants included in the studies. Ethics approval 
was not required as EN studies of this type are covered by a waiver by the Federal Institute for Drugs and Medical Devices (BfArM) in place in Germany.

\section{Test Organisms}

Escherichia coli K 12, NCTC 10538, was used as the test organism in the bactericidal study. E. coli was chosen, as specified by EN1499, since this is the organism that the EN1499 method is validated for in every respect, including volunteers' safety. The contamination fluid used for each test contained between $2.19 \times 10^{8}$ and $5.10 \times 10^{8}$ colony-forming units $(\mathrm{cfu}) / \mathrm{mL}$ E. coli.

MNV Berlin, strain S99 was used as the test organism in the virucidal study. MNV was chosen as the test virus due to the absence of pathogenicity for humans. The host cells used for virus cultivation were RAW 264.7 (murine macrophage cell line). The titers of MNV present in the test suspensions ranged from 7.67 to $8.83 \log _{10}$ tissue culture infectious dose $50 \%$ $\left(\mathrm{TCID}_{50}\right) / \mathrm{mL}$.

\section{Hand-Cleansing Agents}

The test hand cleansing agents in both studies were PVP-I 7.5\% w/v scalp and skin cleanser (Mundipharma Pharmaceuticals, Nicosia, Cyprus) and chlorhexidine gluconate $4 \% \mathrm{w} / \mathrm{v}$ hand cleanser (Mölnlycke Health Care US, Norcross, GA, USA). The reference hand wash procedure used plain soft soap (Sapo kalinus, Pharm. Eur.) $20 \% \mathrm{w} / \mathrm{v}$. Hand cleansing agents were tested undiluted.

\section{Healthy Volunteers}

A total of 15 healthy adult volunteers were screened and enrolled in each study. All volunteers were in general good health with normal skin (free of dermatoses, cuts, lesions, hangnails and other skin disorders), short fingernails ( $<2 \mathrm{~mm}$ in length), no history of skin disease and had not used oral or topical antibiotics within the previous 2 weeks. All volunteers abstained from using antimicrobial products for
7 days prior to testing and during the whole study.

\section{Experimental Design}

The same study design based on EN1499 was used for both studies, with adaptations for viral testing. Randomization to treatment sequence was performed using a Latin Square design. Each volunteer tested each hand cleansing agent and the reference soft soap at 3 and $5 \mathrm{~mL}$ volumes, with each volume tested after washing for 15,30 and $60 \mathrm{~s}$. Testing was repeated weekly, with volunteers testing all three hand cleansing agents at one volume and application time on each of six test days. At the end of the whole series, every volunteer had tested each product, volume and application time once.

\section{Bactericidal Test Method}

The bactericidal test method is summarized in Fig. 1. Testing was performed at $20 \pm 1{ }^{\circ} \mathrm{C}$. Hands were prepared by washing for $60 \mathrm{~s}$ with 5 $\mathrm{mL}$ of soft soap to remove transient bacteria and dried with paper towels. Hands were immersed in the contamination fluid for $5 \mathrm{~s}$ and then allowed to dry in the air for $3 \mathrm{~min}$, avoiding the formation of droplets. Pre-washing samples were obtained by rubbing the fingertips and thumb tips on the base of a Petri dish containing $10 \mathrm{~mL}$ tryptic soy broth (TSB, without neutralizer) for $60 \mathrm{~s}$. A separate dish was used for each hand. Dilutions of $10^{-3}$ and $10^{-4}$ were prepared in TSB and $0.1 \mathrm{~mL}$ of each dilution was plated on the surface of a tryptic soy agar (TSA) plate and incubated at $36^{\circ} \mathrm{C} \pm 1{ }^{\circ} \mathrm{C}$ for $24 \mathrm{~h}$.

Volunteers then washed their wetted hands with test product or reference soft soap following the standard hand wash procedure specified in EN1499. According to EN1499, the standard hand wash procedure was completed by a 10-s rinse of the hands under cold running tap water. Volunteers held their hands with fingertips pointing upwards until post-washing samples were taken by rubbing the fingertips and thumb tips on the base of a Petri dish containing $10 \mathrm{~mL}$ of TSB (with neutralizer) for $60 \mathrm{~s}$. A separate dish was used for each hand. Amounts 


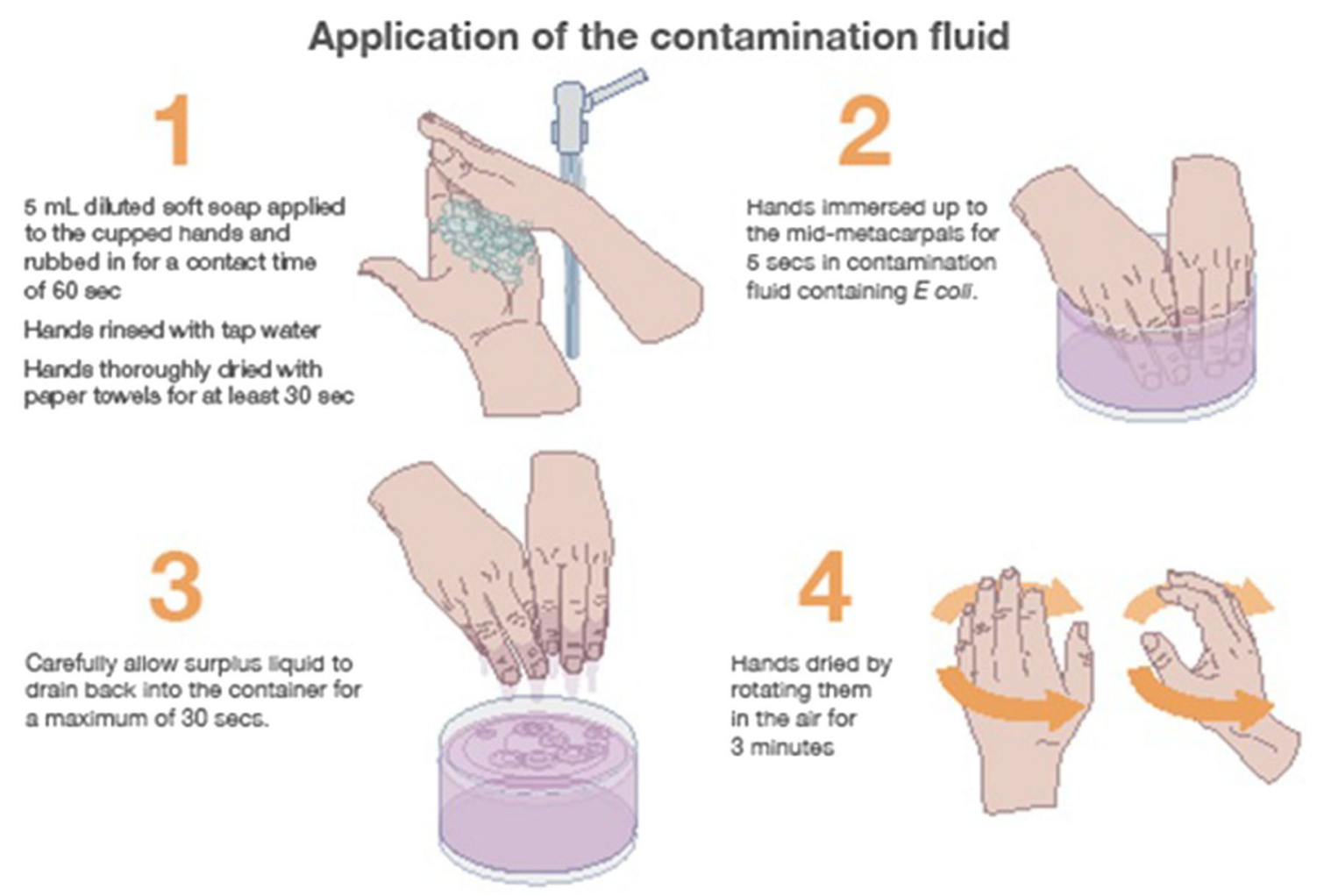

\section{Determination of the prevalues}

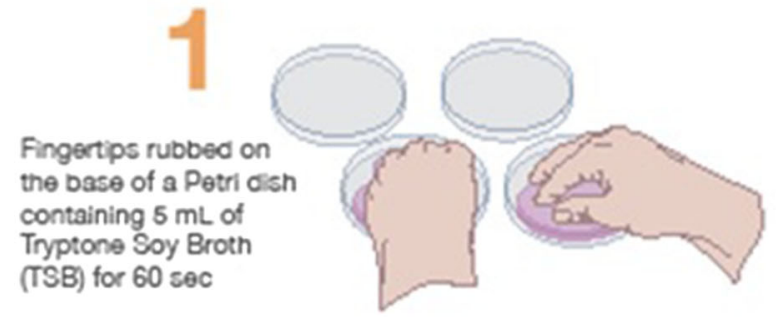

Hygienic hand wash procedure

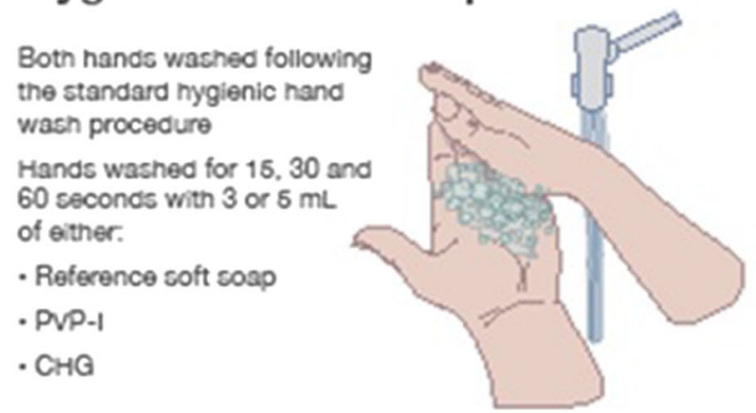

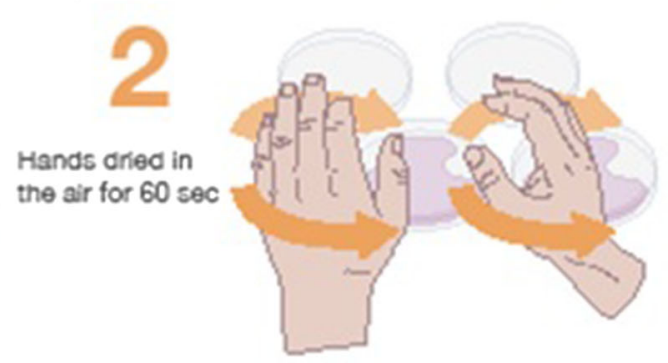

Post value determination step

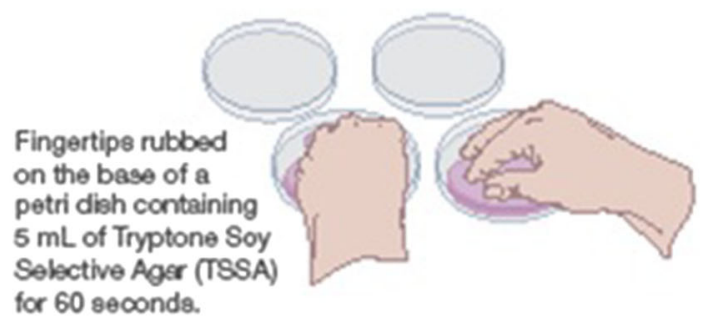

Fig. 1 Bactericidal hygienic hand wash test method and requirements (based on EN1499)

of 1.0 and $0.1 \mathrm{~mL}$ of the undiluted sampling fluid and $0.1 \mathrm{~mL}$ of a $10^{-1}$ dilution were prepared in TSB, plated on the surface of TSA plates and incubated at $36 \pm 1{ }^{\circ} \mathrm{C}$ for $24 \mathrm{~h}$. Neutralizer XXXII $(4 \%$ Tween $80+3 \%$ saponin $+2 \%$ histidine $+0.4 \%$ lecithin $+0.5 \%$ SDS) was used 
for CHG and Neutralizer XLIV $+2 \%$ sodium thiosulfate $\quad(6 \%$ Tween $80+0.2 \%$ histidine $+0.6 \%$ lecithin $+2 \%$ sodium-thiosulfate $+0.2 \% \quad$ peptone $+1.7 \% \quad$ sodium chloride $+1.8 \%$ di-sodium hydrogen phosphate $+0.3 \%$ potassium dihydrogen phosphate) was used for PVP-I.

The number of test organisms released from the fingertips into sampling fluids was assessed before and after the hygienic hand wash and the number of viable bacteria were expressed as cfu per $\mathrm{mL}$. The bactericidal activity was determined by the difference of the mean log prewashing value minus the mean log post-washing value. This difference was given as a reduction factor.

\section{Virucidal Test Method}

The virucidal test method is summarized in Fig. 2. Testing was performed at $20.0 \pm 0.5^{\circ} \mathrm{C}$. To remove transient viruses, $5 \mathrm{~mL}$ of diluted soft soap was applied to the cupped hands of volunteers and was rubbed in for $60 \mathrm{~s}$ before rinsing with tap water and drying with paper towels for $30 \mathrm{~s}$. Hands were inoculated with a low concentration suspension of MNV. Volunteers were asked to cup their hands carefully, $250 \mu \mathrm{L}$ of inoculate was slowly pipetted into the palms, then volunteers gently rubbed their hands together until all surfaces of the hands were coated with the inoculate. Finally, volunteers rotated their hands in the air for $60 \mathrm{~s}$ to allow the inoculate to dry. Pre-washing samples were obtained by rubbing the fingertips of the inoculated hands on the base of a Petri dish containing $5 \mathrm{~mL}$ Dulbeccos Minimum Essential Medium for $60 \mathrm{~s}$, followed by drying hands in the air for $60 \mathrm{~s}$. Volunteers then washed their hands with the test product or reference soft soap following the standard hand wash procedure specified in EN1499 before post-washing samples were obtained using the same methods used pre-washing. The Petri dishes were incubated at $37 \pm 1{ }^{\circ} \mathrm{C}$ under $5 \% \mathrm{CO}_{2}$.

The number of test organisms released from the fingertips into sampling fluids was assessed before and after the hygienic hand wash, and virus titers were expressed $\mathrm{TCID}_{50} / \mathrm{mL}$. The virucidal activity was determined by the difference of the logarithmic titer of the pre-washing sample minus the logarithmic titre of the postwashing sample $\left(\Delta \log _{10} \mathrm{TCID}_{50} / \mathrm{mL}\right)$. This difference was given as a reduction factor.

\section{Statistical Analysis}

The primary endpoint for each study was the mean $\log _{10}$ reduction factor of the test organism after the hand wash with each product at each pre-defined application time $(15,30$ or $60 \mathrm{~s})$ and product volume ( 3 or $5 \mathrm{~mL}$ ). For testing the data obtained in a Latin-square design experiment (where the results of more than one test treatment are compared), the statistical analysis methods proposed in EN1499 [comparison of test treatments with a reference treatment ( $5 \mathrm{~mL}$ soft soap for $60 \mathrm{~s}$ ) in a pairwise manner using a Wilcoxon-Wilcox multiple comparisons test] were applied, although used in an exploratory manner for the virucidal study. The pass criterion for EN1499 was a significance of the observed differences between the test and reference of $p \leq 0.01$. The two test treatments were also compared using the same method in an exploratory manner. The sample size $(n=15)$ was based on the recommendation given in EN1499.

\section{RESULTS}

\section{Bactericidal Testing}

The reference hand wash procedure with $5 \mathrm{~mL}$ soft soap for $60 \mathrm{~s}$ resulted in a mean $\log _{10}$ reduction of $E$. coli of 2.91 . The mean $\log _{10}$ reductions achieved with the test products PVPI and CHG were statistically significantly greater $(p \leq 0.01)$ than the reduction achieved with the reference soft soap for all product volumes and contact times (Table 1). There was no statistically significant difference in mean $\log _{10}$ reduction factors between the different hand washing times using soft soap at either volume ( 3 or $5 \mathrm{~mL}$ ). A small trend towards a greater bacterial reduction with longer washing times 


\section{Application of the contamination fluid}

\begin{abstract}
4
$5 \mathrm{~mL}$ dilisted soft scep appliad to the cupped hends and nubed in for a contect time of $60 \mathrm{sec}$

Hands rineed with tap water Hands thoroughly dried with paper towele for at leest $30 \mathrm{sec}$
\end{abstract}
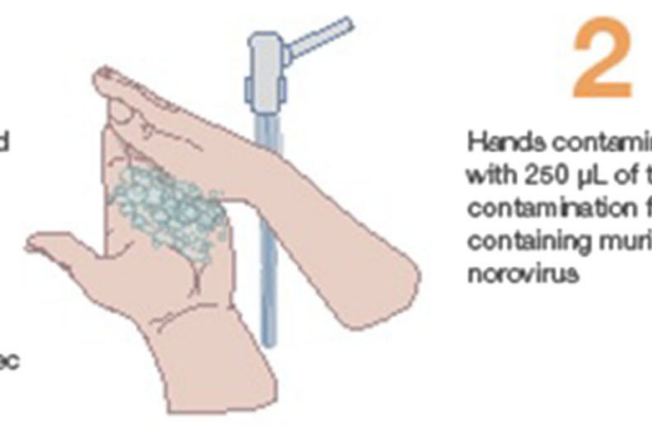

Hends conteminated with $250 \mu \mathrm{L}$ of the contamination fluid containing murine norovirus

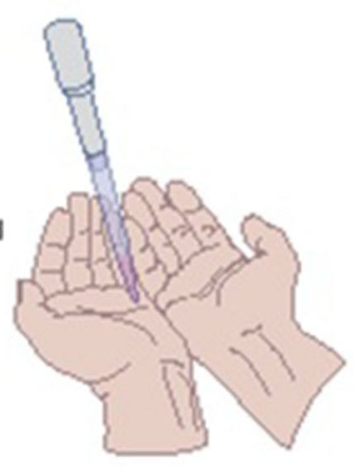

Hands gently rubbed together until all surfaces of the hands were coated with the inoculate
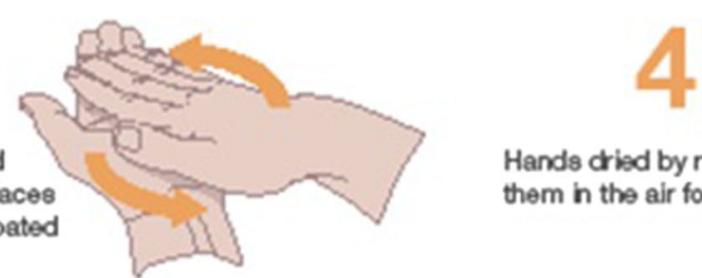

Hands criad by rotating them in the air for $60 \mathrm{sec}$
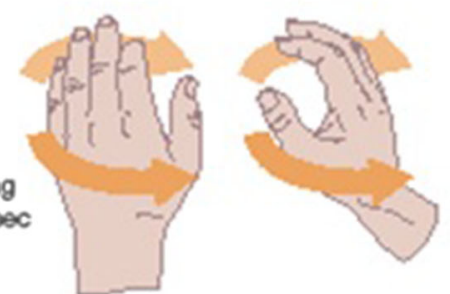

\section{Determination of the prevalues}
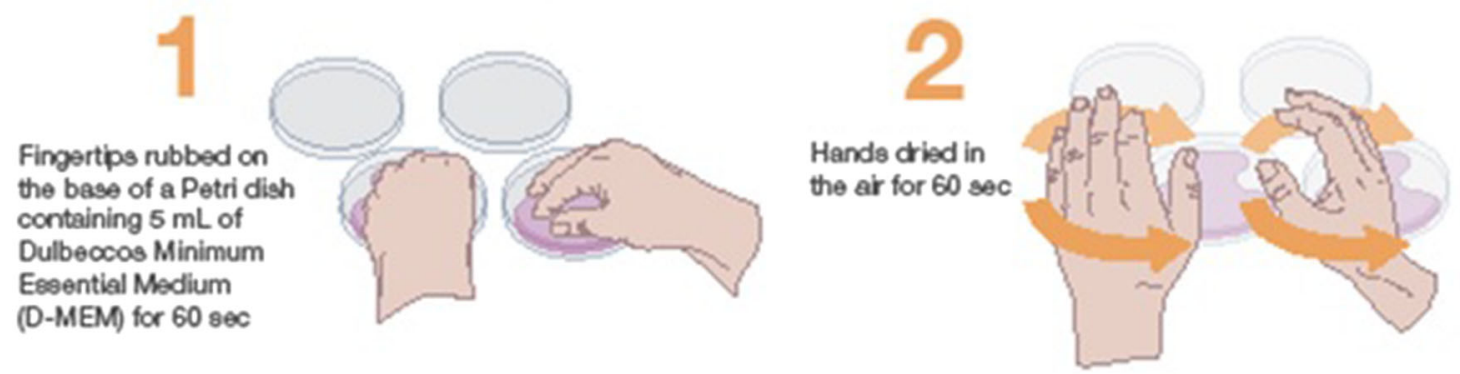

\section{Hygienic hand wash procedure}

\section{Determination of the postvalues}
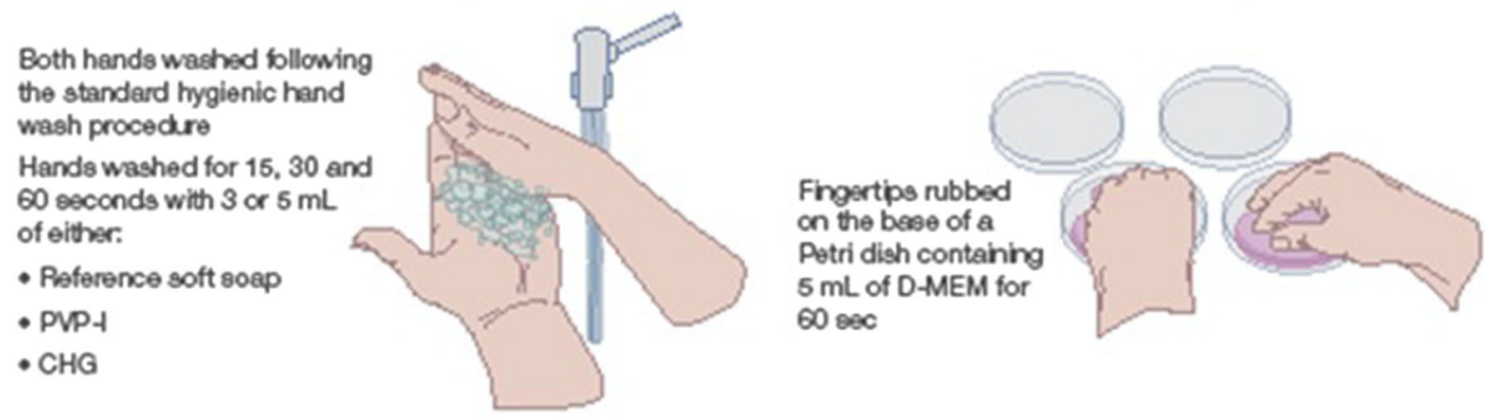

Fig. 2 Virucidal hygienic hand wash test method and requirements (as adapted From EN1499)

was observed for both test products (except $3 \mathrm{~mL}$ CHG; Table 1). An exploratory comparison of PVP-I and CHG showed that there was no statistically significant difference between the two test products for all volumes and time points $(p>0.01)$ (Table 1$)$. 
Table 1 Results of practical hand wash test with Escherichia coli according to EN1499

\begin{tabular}{|c|c|c|c|c|c|c|c|c|c|c|}
\hline \multicolumn{2}{|c|}{ Test parameter } & \multicolumn{3}{|c|}{ Reference soft soap } & \multicolumn{3}{|c|}{ PVP-I } & \multicolumn{3}{|l|}{ CHG } \\
\hline $\begin{array}{l}\text { Product } \\
\text { volume }\end{array}$ & $\begin{array}{l}\text { Contact } \\
\text { time }(s)\end{array}$ & $\begin{array}{l}\text { Pre- } \\
\text { value }\end{array}$ & $\begin{array}{l}\text { Post- } \\
\text { value }\end{array}$ & $\begin{array}{l}\log _{10} \\
\text { reduction }\end{array}$ & $\begin{array}{l}\text { Pre- } \\
\text { value }\end{array}$ & $\begin{array}{l}\text { Post } \\
\text { value }\end{array}$ & $\begin{array}{l}\log _{10} \\
\text { reduction }\end{array}$ & $\begin{array}{l}\text { Pre- } \\
\text { value }\end{array}$ & $\begin{array}{l}\text { Post- } \\
\text { value }\end{array}$ & $\begin{array}{l}\log _{10} \\
\text { reduction }\end{array}$ \\
\hline \multirow[t]{3}{*}{$3 \mathrm{~mL}$} & 15 & 6.05 & 3.24 & 2.80 & 5.99 & 1.90 & $4.09^{\mathrm{b}}$ & 6.03 & 0.81 & $5.22^{\mathrm{b}}$ \\
\hline & 30 & 5.93 & 3.10 & 2.83 & 5.94 & 1.45 & $4.48^{\mathrm{b}}$ & 5.95 & 0.86 & $5.09^{\mathrm{b}}$ \\
\hline & 60 & 5.82 & 2.96 & 2.86 & 5.91 & 1.12 & $4.97^{\mathrm{b}}$ & 6.00 & 0.86 & $5.14^{\mathrm{b}}$ \\
\hline \multirow[t]{3}{*}{$5 \mathrm{~mL}$} & 15 & 6.02 & 2.90 & 3.11 & 5.93 & 1.71 & $4.22^{\mathrm{b}}$ & 6.00 & 1.87 & $4.12^{\mathrm{b}}$ \\
\hline & 30 & 5.89 & 3.14 & 2.75 & 5.81 & 1.49 & $4.32^{\mathrm{b}}$ & 5.97 & 1.64 & $4.33^{\mathrm{b}}$ \\
\hline & 60 & 5.96 & 3.05 & 2.91 & 5.94 & 0.67 & $5.27^{\mathrm{b}}$ & 5.86 & 1.23 & $4.63^{\mathrm{b}}$ \\
\hline
\end{tabular}

Each value represents the mean from 30 samples (left and right hands of 15 volunteers)

CHG chlorhexidine gluconate $4 \%$ hand cleanser, $P V P-I$ povidone-iodine $7.5 \%$ hand cleanser

${ }^{a}$ Mean $\log _{10}$ reduction of post-washing versus pre-washing samples

b Demonstrated a significant difference versus the reference soft soap at the $p=0.01$ level (one-sided), denoting that the test product passes the EN1499 test. The reference procedure with soft soap always used $5 \mathrm{~mL}$ soap for $60 \mathrm{~s}$ contact time per EN1499 standard

\section{Virucidal Testing}

The experimental design using EN1499 is applicable to viral testing with MNV as discriminatory and reproducible results were generated (Table 2).
The reference hand wash procedure with $5 \mathrm{~mL}$ soft soap for $60 \mathrm{~s}$ resulted in a mean $\log _{10}$ reduction factor of 1.44 . The mean $\log _{10}$ reduction factor achieved with PVP-I was significantly greater than the reduction achieved with the reference soft soap ( $p \leq 0.01)$ across all tests, except for the application of $3 \mathrm{~mL}$ for $15 \mathrm{~s}$, for which the reduction achieved was

Table 2 Results of practical hand wash test with murine norovirus according to EN1499

\begin{tabular}{|c|c|c|c|c|c|c|c|c|c|c|}
\hline \multicolumn{2}{|c|}{ Test parameter } & \multicolumn{3}{|c|}{ Reference soft soap } & \multicolumn{3}{|c|}{ PVP-I } & \multicolumn{3}{|l|}{ CHG } \\
\hline $\begin{array}{l}\text { Product } \\
\text { volume }\end{array}$ & $\begin{array}{l}\text { Contact } \\
\text { time }(s)\end{array}$ & $\begin{array}{l}\text { Pre- } \\
\text { value }\end{array}$ & $\begin{array}{l}\text { Post- } \\
\text { value }\end{array}$ & $\begin{array}{l}\log _{10} \\
\text { reduction }\end{array}$ & $\begin{array}{l}\text { Pre- } \\
\text { value }\end{array}$ & $\begin{array}{l}\text { Post } \\
\text { value }\end{array}$ & $\begin{array}{l}\log _{10} \\
\text { reduction }\end{array}$ & $\begin{array}{l}\text { Pre- } \\
\text { value }\end{array}$ & $\begin{array}{l}\text { Post- } \\
\text { value }\end{array}$ & $\begin{array}{l}\log _{10} \\
\text { reduction }\end{array}$ \\
\hline \multirow[t]{3}{*}{$3 \mathrm{~mL}$} & 15 & 5.46 & 4.22 & 1.24 & 5.66 & 4.09 & 1.57 & 5.52 & 4.62 & 0.90 \\
\hline & 30 & 6.33 & 4.71 & 1.62 & 6.41 & 4.28 & $2.13^{\mathrm{b}}$ & 6.04 & 4.87 & 1.18 \\
\hline & 60 & 6.37 & 4.92 & 1.45 & 6.19 & 3.62 & $2.57^{\mathrm{b}}$ & 6.27 & 4.92 & 1.34 \\
\hline \multirow[t]{3}{*}{$5 \mathrm{~mL}$} & 15 & 6.28 & 4.88 & 1.41 & 6.61 & 4.62 & $1.99^{\mathrm{b}}$ & 6.58 & 5.30 & 1.28 \\
\hline & 30 & 5.99 & 4.64 & 1.35 & 6.05 & 4.28 & $1.78^{\mathrm{b}}$ & 5.90 & 4.82 & 1.08 \\
\hline & 60 & 6.27 & 4.83 & 1.44 & 6.00 & 3.81 & $2.19^{\mathrm{b}}$ & 6.12 & 4.83 & 1.28 \\
\hline
\end{tabular}

Each value represents the mean from 30 samples (left and right hands of 15 volunteers)

CHG chlorhexidine gluconate $4 \%$ hand cleanser, PVP-I povidone-iodine $7.5 \%$ hand cleanser

${ }^{a}$ Mean $\log _{10}$ reduction of post-washing versus pre-washing samples

b Demonstrated a significant difference versus the reference soft soap at the $p=0.01$ level (one-sided) in the modified EN1499 test 
numerically but not statistically superior for PVP-I compared with the reference soft soap (Table 2). In contrast, the mean $\log _{10}$ reduction factor with CHG was lower than for the reference soft soap across all tests, and a significant reduction for $\mathrm{CHG}$ compared with the reference soft soap was not achieved (Table 2). A small trend towards a greater viral reduction with longer washing times was observed for both test products (except $5 \mathrm{~mL} \mathrm{CHG}$ ) and soft soap (Table 2). An exploratory comparison of PVP-I and CHG showed that the mean $\log _{10}$ reduction factor achieved with PVP-I was significantly greater than that achieved with CHG $(p \leq 0.01)$ at both 3 and $5 \mathrm{~mL}$ and across all application times.

\section{Safety and Validation}

No adverse events were observed or reported during or after either study. Controls and validations in both studies conformed to EN1499 requirements.

\section{DISCUSSION}

The results of our bactericidal study confirm the positive results with respect to efficacy of PVP-I and $\mathrm{CHG}$ versus plain soap against $E$. coli shown in previous fingertip contamination studies $[32,36]$. However, PVP-I (7.5 or $10 \%)$ has been shown to achieve significantly higher removal rates than CHG 4\% and plain soap against other bacteria, including Staphylococcus aureus, MRSA and $A$. baumannii $[30,31,33,36]$. It should be noted that alcohol rubs have outperformed PVP-I and CHG in removing E.coli in some studies [32, 36, 37].

The findings of our virucidal study are in agreement with the results of a previous study by Steinmann et al. [35] that used MNV as a test organism in a modified finger pad test based on the ASTM E 1838 [34], with modifications derived from the EN1500 [11]. Steinmann et al. found that a PVP-I formulation with $0.75-0.81 \%$ available iodine performed better than three alcohol-based hand rubs, while $4 \%$ CHG and 1\% triclosan hand washes were ineffective [35]. An earlier fingertip test using feline calcivirus (a surrogate for norovirus) by Lages et al. also showed a significantly greater $\log _{10}$ reduction factor for 10\% PVP-I antiseptic compared with two triclosan-containing soaps and five hand sanitizers after $30 \mathrm{~s}$ contact time [38]. A recent review of in vitro and in vivo virucidal activity of ethanol concluded that $80 \%$ ethanol is highly effective against enveloped viruses, MNV and adenovirus type 5 are usually inactivated by $70-90 \%$ ethanol, while $95 \%$ ethanol is required to inactivate most other non-enveloped viruses [39].

Based on the results of our studies and the in vivo studies discussed above, the antimicrobial efficacy of PVP-I appears consistently better than plain soap, whereas CHG performs worse than plain soap against viruses. The soap component of the CHG-containing cleanser should have mechanically reduced the viral count down to a similar level as the reference product, which may go beyond efficacy gaps. The bicationic character of the CHG molecule, that is responsible for adhesion to surfaces and retention of other components as observed in oral use $[40,41]$, may retain viruses too. This retention phenomenon is not only seen with viruses [42] but also with some Gram-negative bacteria such as A. baumannii [31]. It should be noted that, due to the established cumulative effect of CHG $[2,3]$, repeated use may result in greater activity than shown in single-use studies, although repeated use of CHG may also increase its known risk of development of resistance $[2,29,43]$. In contrast, PVP-I demonstrates less persistent activity [2, 3], but is not associated with development of resistance [44].

The method set-up of the EN1499 standard can be considered more robust than the ASTM E method, since it employs an internal standard (i.e., plain soft soap, $5 \mathrm{~mL}$ applied for $60 \mathrm{~s}$ ) with defined success criteria, instead of measuring log reductions alone for pass criteria. Log reductions alone are subject to inherent variability in such complex biological systems as concentration of infected cells in the inoculate and the details of the individual hand wash procedure. The use of an internal standard also allows assessment of the biocidal power of the test product versus the purely mechanical/detergent-based removal of test organisms by non- 
medicated soft soap. Additionally, the EN1499 method has more power to demonstrate efficacy of the products tested due to the larger sample size (15 volunteers) compared with the ASTM E method and several previous fingertip bactericidal studies $[30,31,36]$, which include 5 volunteers. The hand wash procedure was standardized as much as possible in our study by following the CEN procedure (in the meanwhile adapted by WHO) closely, and shorter contact times of 15 and $30 \mathrm{~s}$ were included to more closely reflect real-life use [45-47]. The use of various volumes and exposure times also provided further validation of the internal reference used. We have shown for the first time in this study that the bacterial testing from EN1499 can be adapted to MNV-based viral testing and may be a good basis for further virucidal CEN standards, pending further validation as interlaboratory tests. It may be hypothesized that antiseptic products which are effective against non-enveloped viruses such as MNV will be effective against enveloped viruses such as Ebola (EBOV), severe acute respiratory syndrome and Middle East respiratory syndrome coronaviruses (SARS- and MERS-CoV), influenza and other emerging viruses; this is supported by the results of in vitro suspension tests with the modified vaccinia virus Ankara $[12,13]$.

An obvious limitation of our studies is the use of only a single test pathogen (E. coli and $\mathrm{MNV}$ ). In vivo testing is necessarily restricted to medically safe organisms to minimize the risk to healthy human volunteers, and therefore E. coli (strain NCTC 10538) was chosen as the model pathogen for EN1499. ASTM E1174 [48], the only other standard in vivo method employing the whole hands of human subjects, similarly suggests a single test organism (primarily, Serratia marcescens, or alternatively, E. coli strain ATCC 11229). ASTM E2276 [49] allows for using a variety of medically relevant test species $(S$. marcescens, E. coli, A. baumannii, S. aureus, Staphylococcus epidermidis, Candida albicans, Aspergillus niger), but confines testing to the finger pads rather than the whole hands and only assesses the simple removal of test organisms from the hands with no internal reference. In vitro data on potential efficacy gaps [2] can be taken into consideration given the limitations of in vivo studies.

Another limitation of current in vivo standard test methods, including EN1499, is that they do not account for extrinsic factors such as protein load on soiled hands, residual activity (a notable characteristic of CHG [2]) and how the product is used/applied by individuals [3]. It should also be emphasized that the degree of reduction in microbial counts required to produce a meaningful drop in the hand-borne spread of nosocomial pathogens has yet to be quantified, and thus the clinical relevance of such in vivo test results remains unclear $[23,24]$. Controlled clinical, observational and epidemiological studies are thus needed for more direct proof of clinical effectiveness, but are generally lacking, although PVP-I hand scrub has previously been shown to have superior efficacy to soap and water in a neonatal intensive care unit [50].

Another important consideration in selection of hand hygiene agents, particularly in resource-poor countries, is cost and availability. Alcohol-based hand rub formulations proposed by the WHO have recently been shown to be effective against enveloped viruses including emerging Zika, EBOV, SARS-CoV and MERS$\mathrm{CoV}$ in vitro [51], and may be a more freely available and cost-effective alternative to medicated cleansers/antiseptics. Since hand rubs cannot properly cleanse soiled hands [2], a phased approach as recommended by the National Institute for Health and Care Excellence [52] may be an optimized approach to handle situations where increased hand hygiene is warranted.

\section{CONCLUSION}

In conclusion, in these simulated hand wash studies, PVP-I $7.5 \%$ scalp and skin cleanser passed the requirements of EN1499 (adapted for viruses) and showed significantly better efficacy against $E$. coli and MNV than the reference soft soap within $15 \mathrm{~s}$ using a 3-mL application (E. coli) or a 5-mL application (MNV). CHG 4\% hand cleanser also passed the requirements of EN1499 against E. coli within $15 \mathrm{~s}$ using a 3-mL 
application, but was ineffective against MNV compared to hand washing with soft soap. Although the results have yet to be confirmed in clinical and epidemiological studies, these studies provide important public health information for the appropriate use of hand hygiene products.

\section{ACKNOWLEDGEMENTS}

We thank the participants of the studies. Special thanks are given to Carolin Benzinger, Sarah Bachmeier and Birgit Ahrens who helped conduct the study at the Laboratory Enders, for their excellent technical assistance.

Funding. Sponsorship for both studies and article processing charges was funded by Mundipharma Manufacturing Pte Ltd. All authors had full access to all of the data in this study and take complete responsibility for the integrity of the data and accuracy of the data analysis.

Editorial Assistance. Editorial assistance in the preparation of this article was provided by Karen Mower of Scientific Editorial. Support for this assistance was funded by Mundipharma Research GmbH \& Co.KG.

Authorship. All named authors meet the International Committee of Medical Journal Editors (ICMJE) criteria for authorship for this article, take responsibility for the integrity of the work as a whole, and have given their approval for this version to be published.

Prior Presentation. This work has been presented at the 2nd International Meetings on Respiratory Pathogens, Singapore, 7-9 March 2018.

Disclosures. Hygiene Nord GmbH and Laboratory Enders performed the studies on behalf of the sponsor, Mundipharma Manufacturing Pte Ltd. Maren Eggers was paid travel expenses and honorarium by Mundipharma Manufacturing Pte Ltd. Torsten Koburger-Janssen is an employee of Hygiene Nord GmbH. Lois Ward is an employee of Mundipharma Research Limited. Craig Newby is an employee of Mundipharma Manufacturing Pte Ltd. Stefan Müller is an employee of Mundipharma Research $\mathrm{GmbH}$ $\&$ Co.KG.

Compliance with Ethics Guidelines. All procedures performed in studies involving human participants were in accordance with the 1964 Helsinki declaration and its later amendments or comparable ethical standards. Informed consent was obtained from all individual participants included in the studies. Ethics approval was not required as EN studies of this type are covered by a waiver by the Federal Institute for Drugs and Medical Devices (BfArM) in place in Germany.

Open Access. This article is distributed under the terms of the Creative Commons Attribution-NonCommercial 4.0 International License (http://creativecommons.org/licenses/ by-nc/4.0/), which permits any noncommercial use, distribution, and reproduction in any medium, provided you give appropriate credit to the original author(s) and the source, provide a link to the Creative Commons license, and indicate if changes were made.

\section{REFERENCES}

1. Kampf G, Kramer A. Epidemiologic background of hand hygiene and evaluation of the most important agents for scrubs and rubs. Clin Microbiol Rev. 2004;17:863-93.

2. World Health Organization. WHO guidelines on hand hygiene in health care. 2009. http://www.who. int/gpsc/5may/tools/9789241597906/en/. Accessed March 2018.

3. Boyce JM, Pittet D. Centers for Disease Control and Prevention. Guideline for hand hygiene in healthcare settings: recommendations of the Healthcare Infection Control Practices Advisory Committee and the HICPAC/SHEA/APIC/IDSA Hand Hygiene Task Force. MMWR Morbid Mortal Wkly Rep. 2002;51(RR-16):1-45.

4. Ejemot-Nwadiaro RI, Ehiri JE, Arikpo D, Meremikwu MM, Critchley JA. Hand washing 
promotion for preventing diarrhoea. Cochrane Database Syst Rev. 2015;9:CD004265.

5. Centers for Disease Control and Prevention. 2002. Guidelines for Hand Hygiene in Health-Care Settings. https://www.cdc.gov/mmwr/PDF/rr/rr5116. pdf. Accessed March 2018.

6. World Health Organization. 2014. Interim infection prevention and control guidance for care of patients with suspected or confirmed filovirus haemorrhagic fever in health-care settings, with focus on Ebola. http://www.who.int/csr/resources/ publications/ebola/filovirus_infection_control/en/. Accessed March 2018.

7. Sickbert-Bennett EE, Weber DJ, Gergen-Teague MF, Rutala WA. The effects of test variables on the efficacy of hand hygiene agents. Am J Infect Control. 2004;32:69-83.

8. EN1276:2009. Chemical disinfectants and antiseptics. Quantitative suspension test for the evaluation of bactericidal activity of chemical disinfectants and antiseptics used in food, industrial, domestic and institutional areas. Test method and requirements (Phase 2, Step 1).

9. EN14476:2013/FprA1:2015. Chemical disinfectants and antiseptics. Quantitative suspension test for the evaluation of virucidal activity in the medical area. Test method and requirements (Phase 2, Step 1).

10. EN1499:2013: Chemical disinfectants and antiseptics. Hygienic handwash. Test method and requirements (Phase 2, Step 2).

11. EN1500:2013. Chemical disinfectants and antiseptics. Hygienic handrub. Test method and requirements (Phase 2, Step 2).

12. Eggers M, Eickmann M, Kowalski K, Zorn J, Reimer K. Povidone-iodine hand wash and hand rub products demonstrated excellent in vitro virucidal efficacy against Ebola virus and modified vaccinia virus Ankara, the new European test virus for enveloped viruses. BMC Infect Dis. 2015;15:375.

13. Eggers M, Eickmann M, Zorn J. Rapid and effective virucidal activity of povidone-iodine products against middle east respiratory syndrome coronavirus (MERS-CoV) and modified vaccinia virus Ankara (MVA). Infect Dis Ther. 2015;4:491-501.

14. McLure AR, Gordon J. In-vitro evaluation of povidone-iodine and chlorhexidine against methicillinresistant Staphylococcus aureus. J Hosp Infect. 1992;21:291-9.

15. Traoré O, Fayard SF, Laveran H. An in vitro evaluation of the activity of povidone-iodine against nosocomial bacterial strains. J Hosp Infect. 1996;34:217-22.

16. Shimizu M, Okuzumi K, Yoneyama A, et al. In vitro antiseptic susceptibility of clinical isolates from nosocomial infections. Dermatology. 2002;204(Suppl 1):21-7.

17. Gorman SP, Scott EM, Hutchinson EP. Effects of aqueous and alcoholic povidone-iodine on spores of Bacillus subtilis. J Appl Bacteriol. 1985;59:99-105.

18. Rikimaru T, Kondo M, Kondo S, Oizumi K. Bactericidal activities of povidone-iodine against Mycobacterium. Dermatology. 1997;195(Suppl 2):104-6.

19. Wutzler P, Sauerbrei A, Klöcking R, Brögmann B, Reimer K. Virucidal activity and cytotoxicity of the liposomal formulation of povidone-iodine. Antiviral Res. 2002;54:89-97.

20. Kawana R, Kitamura T, Nakagomi O, et al. Inactivation of human viruses by povidone-iodine in comparison with other antiseptics. Dermatology. 1997;195(Suppl 2):29-35.

21. Kariwa H, Fujii N, Takashima I. Inactivation of SARS coronavirus by means of povidone-iodine, physical conditions and chemical reagents. Dermatology. 2006;212(Suppl 1):119-23.

22. Shimizu M, Okuzumi K, Yoneyama A, et al. In vitro antiseptic susceptibility of clinical isolates from nosocomial infections. Dermatology. 2002;204(Suppl 1):21-7.

23. Rotter M. Hand washing and hand disinfection. In: Mayhall CG, editor. Hospital epidemiology and infection control. 2nd ed. Philadelphia: Lippincott Williams \& Wilkins; 1999. p. 1339-55.

24. Larson EL. APIC guideline for handwashing and hand antisepsis in health care settings. Am J Infect Control. 1995;23:251-69.

25. Platt J, Bucknall RA. The disinfection of respiratory syncytial virus by isopropanol and a chlorhexidinedetergent handwash. J Hosp Infect. 1985;6:89-94.

26. Denton GW. Chlorhexidine. In: Block SS, editor. Disinfection, sterilization and preservation. 4th ed. Philadelphia: Lea \& Febiger; 1991. p. 274-89.

27. Krilov LR, Hella Harkness SH. Inactivation of respiratory syncytial virus by detergents and disinfectants. Pediatr Infect Dis J. 1993;12:582-4.

28. Narang HK, Codd AA. Action of commonly used disinfectants against enteroviruses. J Hosp Infect. 1983;4:209-12. 
29. Kampf G. Acquired resistance to chlorhexidine-is it time to establish an 'antiseptic stewardship' initiative? J Hosp Infect. 2016;94:213-27.

30. Guilhermetti M, Hernandes SE, Fukushigue Y, Garcia LB, Cardoso CL. Effectiveness of handcleansing agents for removing methicillin-resistant Staphylococcus aureus from contaminated hands. Infect Control Hosp Epidemiol. 2001;22:105-8.

31. Cardoso CL, Pereira HH, Zequim JC, Guilhermetti M. Effectiveness of hand-cleansing agents for removing Acinetobacter baumannii strain from contaminated hands. Am J Infect Control. 1999;27:327-31.

32. Aycliffe GA, Babb JR, Davies JG, Lilly HA. Hand disinfection: a comparison of various agents in laboratory and ward studies. J Hosp Infect. 1988;11:226-43.

33. Huang Y, Oie S, Kamiya A. Comparative effectiveness of hand-cleansing agents for removing methicillin-resistant Staphylococcus aureus from experimentally contaminated fingertips. Am J Infect Control. 1994;22:224-7.

34. ASTM E 1838-17. Standard test method for determining the virus-eliminating effectiveness of hygienic handwash and handrub agents using the fingerpads of adults. ASTM International, West Conshohocken, PA, 2017.

35. Steinmann J, Paulmann D, Becker B, Bischoff B, Steinmann E, Steinmann J. Comparison of virucidal activity of alcohol-based hand sanitizers versus antimicrobial hand soaps in vitro and in vivo. J Hosp Infect. 2012;82:277-80.

36. Aycliffe GAJ, Babb JR, Quoraishi AH. A test for hygienic hand disinfection. J Clin Pathol. 1978;31:923-8.

37. Rotter ML, Koller W, Wewalka G, Werner HP, Aycliffe GA, Babb JR. Evaluation of procedures for hygienic hand-disinfection: controlled parallel experiments on the Vienna test model. J Hyg (Lond). 1986;96:27-37.

38. Lages SL, Ramakrishnan MA, Goyal SM. In-vivo efficacy of hand sanitisers against feline calcivirus: a surrogate for norovirus. J Hosp Infect. 2008;68:159-63.

39. Kampf G. Efficacy of ethanol against viruses in hand disinfection. J Hosp Infect. 2018;98:331-8.

40. Van Strydonck DA, Slot DE, Van der Velden U, Van der Weijden F. Effect of a chlorhexidine mouthrinse on plaque, gingival inflammation and staining in gingivitis patients: a systematic review. J Clin Periodontol. 2012;39:1042-55.
41. Zanatta FB, Antoniazzi RP, Rösing CK. Staining and calculus formation after $0.12 \%$ chlorhexidine rinses in plaque-free and plaque covered surfaces: a randomized trial. J Appl Oral Sci. 2010;18:515-21.

42. Steinmann J, Becker B, Bischoff B, Paulmann D, Steinmann J, Steinmann E. Alte und neue Erkenntnisse zur Virus-Wirksamkeit der hygienischen Händedesinfektion. Hyg Med. 2009;34:32-40.

43. Thomas L, Maillard JY, Lambert RJ, Russell AD. Development of resistance to chlorhexidine diacetate in Pseudomonas aeruginosa and the effect of a 'residual' concentration. J Hosp Infect. 2000;46:297-303.

44. Lanker Klossner B, Widmer HR, Frey F. Nondevelopment of resistance by bacteria during hospital use of povidone-iodine. Dermatology. 1997;195(Suppl 2):10-3.

45. Kampf G. The puzzle of volume, coverage, and application time in hand disinfection. Infect Control Hosp Epidemiol. 2017;38:880-1.

46. Quraishi ZA, McGuckin M, Blais FX. Duration of handwashing in intensive care units: a descriptive study. Am J Infect Control. 1984;12:83-7.

47. Meengs MR, Giles BK, Chisholm CD, Cordell WH, Nelson NR. Handwashing frequency in an emergency department. Ann Emerg Med. 1994;23:1307-12.

48. ASTM E1174-13. Standard test method for evaluation of the effectiveness of health care personnel handwash formulations. ASTM International, West Conshohocken, PA, 2013.

49. ASTM E2276-10. Standard test method for determining the bacteria-eliminating effectiveness of hygienic handwash and handrub agents using the fingerpads of adults. ASTM International, West Conshohocken, PA, 2010.

50. Sharma VS, Dutta S, Taneja N, Narang A. Comparing hand hygiene measures in a neonatal ICU: a randomized crossover trial. Indian Pediatr. 2013;50:917-21.

51. Siddharta A, Pfaender S, Vielle NJ, et al. Virucidal activity of World Health Organization-recommended formulations against enveloped viruses, including Zika, Ebola, and Emerging Coronaviruses. J Infect Dis. 2017;215:902-6.

52. National Institute for Health and Care Excellence. 2012. Healthcare-associated infections: prevention and control in primary and community care. https:// www.nice.org.uk/guidance/cg139/resources/health careassociated-infections-prevention-and-control-inprimary-and-community-care-pdf-35109518767045. Accessed March 2018. 